\title{
Thirty years of Biology \& Philosophy: \\ Philosophy of which biology?
}

Final draft. To appear in Biology and Philosophy.

\author{
Thomas Pradeu \\ - ImmunoConcept, CNRS \& University of Bordeaux, 146 rue Léo Saignat 33076 \\ Bordeaux, France \\ - Institut d'histoire et de philosophie des sciences et des techniques, CNRS \& \\ Panthéon-Sorbonne University, 11 rue du Four 75006, France
}

Email: thomas.pradeu@u-bordeaux.fr

Phone: +33-5-5757-9547

Fax: $+33-5-5757-1472$

\begin{abstract}
Which domains of biology do philosophers of biology primarily study? The fact that philosophy of biology has been dominated by an interest for evolutionary biology is widely admitted, but it has not been strictly demonstrated. Here I analyse the topics of all the papers published in Biology \& Philosophy, just as the journal celebrates its thirtieth anniversary. I then compare the distribution of biological topics in Biology \& Philosophy with that of the scientific journal Proceedings of the National Academy of Science of the USA, focusing on the recent period 2003-2015. This comparison reveals a significant mismatch between the distributions of these topics. I examine plausible explanations for that mismatch. Finally, I argue that many biological topics underrepresented in philosophy of biology raise important philosophical issues and should therefore play a more central role in future philosophy of biology.
\end{abstract}

Keywords

Biology \& Philosophy; Philosophy of biology; History of philosophy of biology.

\section{Acknowledgments}

I would like to thank Jean Gayon for his inspiring work. In addition, I would like to thank Lynn Chiu, Jean Gayon, Peter Godfrey-Smith, Matt Haber, Philippe Huneman, Maureen O'Malley, Sahotra Sarkar, and two anonymous referees for their comments on previous drafts. Dick Burian and Jean Gayon also provided very useful information about the history of ISHPSSB. This project has received funding from the European Research Council (ERC) under the European Union's Horizon 2020 research and innovation programme - grant agreement $n^{\circ} 637647$ - IDEM. 


\section{Introduction}

Even though the phrase "philosophy of biology" was coined by Whewell in 1840 (Gayon 2009) and despite the fact that interesting philosophical and conceptual explorations of biology appeared between the $1920 \mathrm{~s}$ and $1960 \mathrm{~s}^{1}$, philosophy of biology only emerged as a well-identified domain in the Anglo-Saxon world during the 1970s, and has since then blossomed (Hull 2008). Today, philosophy of biology has its own international society, the International Society for the History, Philosophy, and Social Studies of Biology (ISHPSSB, founded in 19892), and it is disseminated in several academic journals, the most representative of which is certainly Biology \& Philosophy, launched by Michael Ruse in 1986 (Ruse was the editor of the journal from 1986 to 2000; Kim Sterelny has been the editor from 2000 until January 2017).

A special feature of philosophy of biology is that it is closely tied to biology as it is practised. Several founders, in particular Hull (1969), insisted that philosophers of biology should be well informed by the most recent biological results, and, if possible, offer analyses that are interesting and useful for biologists themselves. Philosophers of biology often publish their papers in scientific journals, and some of them are widely cited by biologists. Reciprocally, a number of biologists (including Ernst Mayr, Richard Lewontin, and Francisco Ayala) have played a major role in the content and the institutional organization of philosophy of biology, and it is not rare for biologists to publish papers in a journal such as Biology \& Philosophy (examples include Richard Dawkins, Richard Lewontin, David Haig, and Richard Michod, among many others).

But which domains of biology are philosophers of biology interested in? It has often been observed that philosophy of biology is dominated by evolutionary studies, but the extent and exact nature of this domination have not been carefully analysed. In addition, it seems useful to describe in detail the respective role other biological domains play in philosophy of biology. To address these issues, I analyse all the papers published in Biology \& Philosophy since the journal was launched in 1986, exactly thirty years ago. I show that two topics are dominant: evolution and, to a much lesser extent, the psychological and cognitive sciences. I then compare this distribution of papers in Biology \& Philosophy with the distribution of papers published by a major generalist scientific journal, the Proceedings of the National Academy of Science of the USA (hereafter PNAS), during the same period ${ }^{3}$. This analysis shows that there is a significant mismatch between the topics studied by biologists and those studied by philosophers of biology (as reflected in Biology \& Philosophy). I examine explanations that have been or could be advanced to account for this mismatch, and I show that many of them are unconvincing. In particular, the

\footnotetext{
${ }^{1}$ This includes the work of Woodger (1929), Beckner (1959), and Goudge (1961), among others. Importantly, Byron (2007) has shown that, contrary to common thought, biological questions have not been entirely neglected by philosophers of the logical positivist period.

${ }^{2}$ The first meeting of the group that eventually became the ISHPSSB was held at Virginia Tech in 1983, but the ISHPSSB was officially named in 1989 and its governance was formalized in 1990. I am grateful to Dick Burian for his detailed account about this history.

${ }^{3}$ Naturally, the methodology used in this paper is extremely simple, and it would not be approved by statisticians. Moreover, I analysed the data of only one journal in philosophy of biology, Biology \& Philosophy (based on the argument that it is the only journal devoted exclusively to philosophy of biology), but it is clear that philosophy of biology is often published in other journals, so my conclusions do not necessarily apply to philosophy of biology as a whole.
} 
idea that biological fields not focusing directly on evolution do not raise important philosophical problems is ruled out, on the basis of several examples. My conclusion is that philosophers of biology should widen their perspectives, and complement the work done about evolutionary biology by investigations about a variety of other biological fields, as this would lead to a richer and more integrative philosophy of biology.

\section{What domains of biology do philosophers of biology study?}

In this section, I analyse the distribution of biological domains reflected by all the papers published in Biology \& Philosophy in the last thirty years, starting from 1986. For the period between 1986 and 2002, I reconstructed an analysis made by Jean Gayon (2009). For the period between 2003 and 2015, I carried out my own analysis.

Biological domains in Biology \& Philosophy from 1986 to 2002

Gayon (2009) analysed the themes of all the papers published in Biology \& Philosophy from 1986 to 2002. Here I recall Gayon's methodology and his main results. From 1986 to 2002, Biology \& Philosophy published a total of 421 papers, that is, on average 25 papers per year. Gayon classified all the papers published in Biology \& Philosophy during this period into three broad categories: "Studies on particular biological theories, concepts or methods" (approximately 48\%); "Philosophical questions of general interest regarding biology and the living world" (approximately 37\%); "Articles with a clear historical dimension" (approximately $15 \%$ ). The first category was then divided into six subcategories: Evolution; Taxonomy; Species; Ecology; Genetics; Other (which includes development, psychology, physiology, cognitive sciences, etc.). The second category was also divided into six categories: Evolutionary epistemology; Ethics and biology (especially evolutionary ethics); Nature/culture; Function, teleology, design; Reflections in biology in general (laws, autonomy of biology, etc.); Other (which includes philosophy of mind, emotions, religion, etc.).

Gayon's main conclusions (2009: 208-209) were that:

- $72 \%$ of the thematic papers published in Biology \& Philosophy from 1986 to 2002 (those belonging to the category "Studies on particular biological theories, concepts or methods") deal with evolution broadly speaking.

- Physiology, biochemistry, and biophysics are strikingly absent.

- There is no significant change in the representation of the different biological domains over time.

- This stability suggests that philosophers of biology are not particularly sensitive to scientific novelty in biology over time.

Because my main aim here was to offer a comprehensive view of the biological domains represented in the papers published in Biology \& Philosophy, I reconstructed, with Gayon's help, the tables found in (Gayon 2009). First, I did not use the three broad categories mentioned above; instead, I re-classified all the papers into 10 categories, to better reflect all the diverse biological areas found in Biology \& Philosophy. The 10 categories are: Evolution; Taxonomy; Species; Ecology; 
Genetics; Evolutionary epistemology; Evolutionary ethics; Function, teleology, design; Reflections on biology in general; Others (which, here, includes papers dealing with some underrepresented areas of biology, e.g., development or physiology, strictly historical papers, and papers that are of a very general philosophical nature). Second, I re-examined carefully all the papers published from 1986 to 2002, and, with Gayon's help, I made some important corrections to his original data.

The details of these modified data appear in Table S1 (see Supplementary material). The main results appear in Figure 1, and can be summarized as follows:

- $24.5 \%$ of all the papers published in Biology \& Philosophy from 1986 to 2002 were about evolution strictly speaking.

- $55 \%$ of the papers published in Biology \& Philosophy from 1986 to 2002 were about evolution broadly construed, which includes the species problem, taxonomy, evolutionary epistemology, and evolutionary ethics.

- Domains such as physiology, biochemistry, and biophysics are absent.

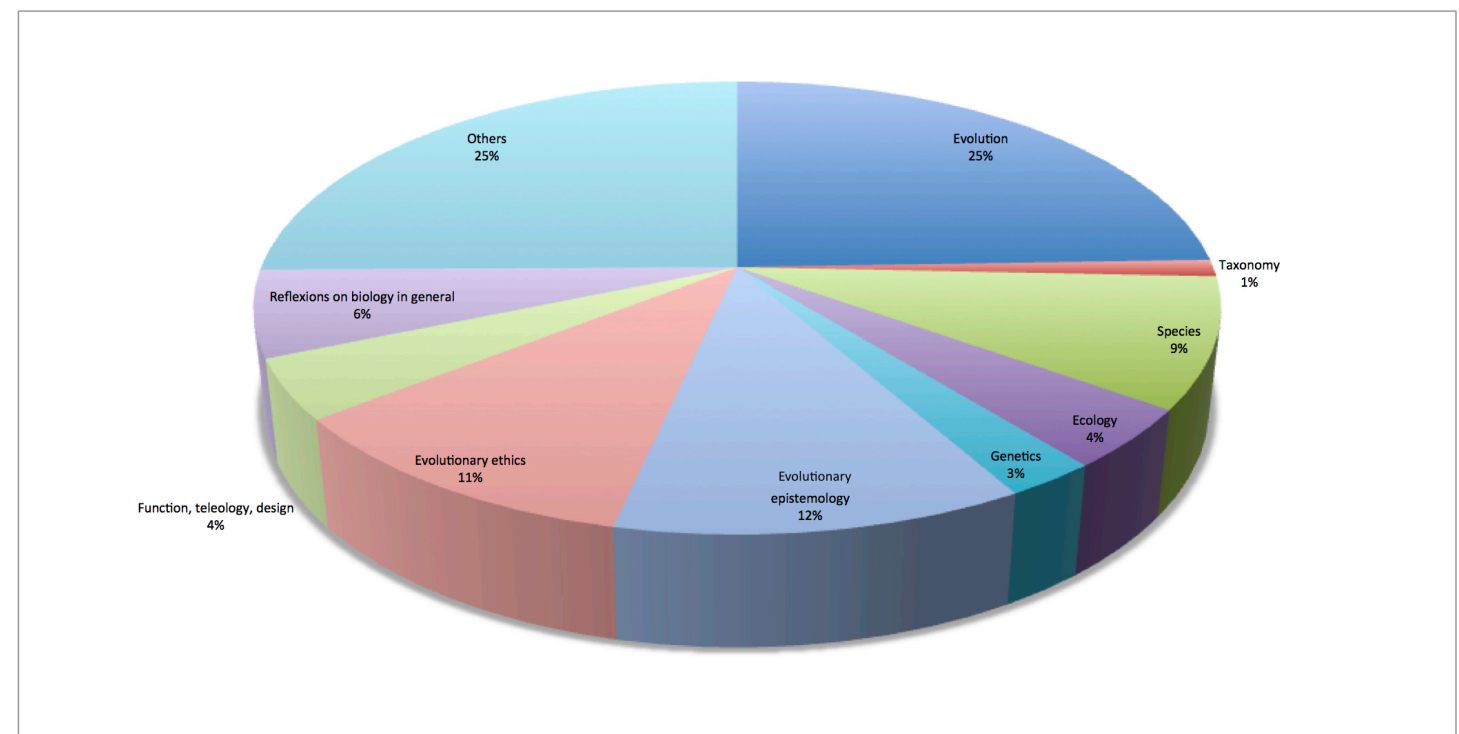

Figure 1: Biological domains represented in Biology \& Philosophy from 1986 to 2002 (based on (Gayon 2009)).

The next step was to analyse the evolution of this distribution of domains beyond 2002. Do Gayon's conclusions still apply? Does evolution still dominate philosophy of biology? Did some of the new developments of biology in the 2000s modify the topics of interest to philosophers of biology? In an attempt to address these questions, the next subsection analyses the papers published in Biology \& Philosophy from 2003 to 2015 .

Biological domains in Biology \& Philosophy from 2003 to 2015

From 2003 to 2015, 499 papers were published in Biology \& Philosophy, 38 papers per year on average. I start with a few explanations about the methodology that I adopted. The main difference with Gayon's analysis is that I did not use categories 
and subcategories. I used a total of 23 categories $^{4}$, reflecting directly those of the scientific journal $P N A S$, in order to enable the systematic comparison between the representation of biological domains in the two journals, which constitutes the main objective of Section 3. Therefore, the categories used here are: Agricultural sciences; Anthropology; Applied biological sciences; Biochemistry; Biophysics and computational biology; Cell biology; Developmental biology; Ecology; Environmental sciences; Evolution; Genetics; Immunology; Medical sciences; Microbiology; Neuroscience; Pharmacology; Physiology; Plant biology; Population biology; Psychological and cognitive sciences; Sustainability science; Systems biology; and Others 5 .

Moreover, I followed Gayon in excluding book reviews, unless a whole issue or a whole section of the journal was devoted to a particular book, because I considered that in those cases the theme of the book had been deemed by the editor of Biology \& Philosophy to be of broad interest for the community of philosophers of biology. Editorials of a very general nature have been excluded. However, editors' introductions to special issues were included, as they often offered arguments explaining the importance of the special issue theme.

What are the main results of this analysis? Table S2 (Supplementary material) gives a detailed account of the biological domains represented in Biology \& Philosophy from 2003 to 2015. Figure 2 shows the main results, which can be summarized as follows:

- $62 \%$ of the papers published in Biology \& Philosophy from 2003 to 2015 were about evolution. More precisely, $41 \%$ were about evolution in general, $6 \%$ about systematics and the species problem, and $15 \%$ about human evolution (including evolutionary psychology, evolutionary ethics, and cultural evolution).

- $14 \%$ of the papers published in Biology \& Philosophy from 2003 to 2015 were about psychological and cognitive sciences.

- Many biological domains were absent or virtually absent, including biophysics and computational biology, cell biology, immunology, physiology, and systems biology.

- Some biological domains were represented only or mainly because a special issue had been devoted to them. Two clear examples concerned developmental biology (7 of a total of 19 papers about development from 2003 to 2015 belong to a single special issue on 'evo-devo', edited by Sahotra Sarkar and Jason Robert in March 2003, which could effectively have been counted as about evolution), and microbiology (12 of a total of 13 papers about

\footnotetext{
${ }^{4}$ In my counting, my guiding question was always: What domain of biological sciences (if any) is used (or mainly used)? In most cases, this question was not problematic, as the papers were indeed exploring a specific biological domain. In a very limited number of cases, it was a bit trickier, in particular when the main theme of the paper was a general question, using biological domains in a rather distant way (as, for example, when a paper would raise the general issue of whether or not there are biological laws, without using a particular field to address this question). But, again, this situation was rare.

${ }^{5}$ The category "Others" includes papers that analyse problems of general philosophy of science applied to biology (e.g., causality, information, reductionism, emergence, theories-models, laws, mechanisms, functions). If a paper had a general scope but was based on an extensive analysis of one given biological domain, it was classified in the corresponding entry (e.g., a paper on reductionism in developmental biology appears in the "Developmental biology" entry).
} 
microbiology from 2003 to 2015 belong to a single special issue on "Philosophy and the Microbe" edited by Maureen O’Malley in March 2013).

- The presence of some domains increased over time. This includes the psychological and cognitive sciences, as well as microbiology (even though in the latter case it is due almost exclusively to the single special issue mentioned above). Other domains were stable over time.

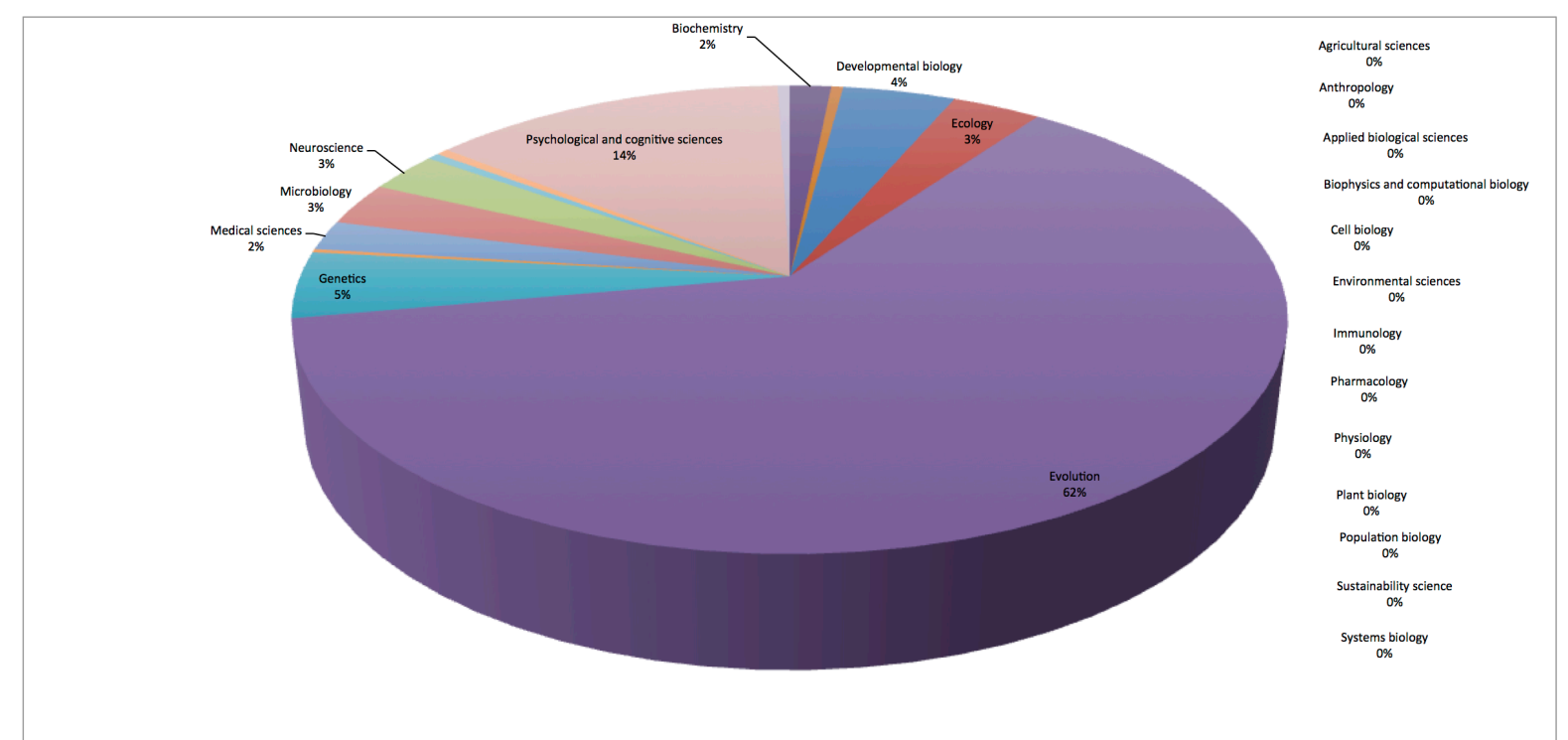

Figure 2: Biological domains represented in Biology \& Philosophy from 2003 to 2015.

Before attempting to explain the domination of evolutionary biology in the work of philosophers of biology ${ }^{6}$, it seems useful to compare the representation of biological fields in philosophy of biology and in biology itself. Which biological domains are more represented in scientific journals? Does the distribution of biological topics in Biology \& Philosophy reflect the distribution of biological topics found in a major biology journal? To address this issue, the next section makes a systematic comparison between Biology \& Philosophy and the journal Proceedings of the National Academy of Sciences of the USA (hereafter PNAS).

\section{The discrepancy between today's philosophy of biology and biology}

To get a more precise idea about how philosophers of biology see biology, it is useful to compare the distribution of biological domains in Biology \& Philosophy to that found in a scientific journal. PNAS is an appropriate choice, for several reasons. Launched in 1915 as the official scientific journal of the National Academy of Sciences of the USA and published weekly ever since, it is highly respected in the broad scientific community ${ }^{7}$. More importantly for the present study, PNAS uses a

\footnotetext{
${ }^{6}$ Interestingly, this domination of evolution in philosophy of biology seems to go against the intentions of the two successive editors of Biology \& Philosophy, Michael Ruse and Kim Sterelny. In his first editorial, Sterelny mentions his desire to continue Ruse's project to not focus exclusively on evolution. 7 PNAS is particularly respected by evolutionists, and this journal publishes many papers about evolution, which was important to avoid any bias.
} 
discipline-based system of classification for the papers it publishes (called "Sections" in PNAS), unlike many other scientific journals". As explained above, I used PNAS's 22 categories to classify biological papers to classify the papers of Biology \& Philosophy as well.

How are different biological fields represented in PNAS? Table $\mathbf{S 3}$ (Supplementary material) shows this representation over the periods 1986-2002 and 2003-2015. Nonetheless, because my main purpose was comparative and because PNAS used systematically its classification system only starting from 1996, the present analysis focuses on the period 2003-2015 (that is, the same as the one used above about Biology \& Philosophy). During this period, PNAS published a total of 51,896 papers, 42,934 of which were about biology (approximately 83\%). Table S4 (Supplementary material) details, for each domain, the number of papers and the percentage with regard to the total number of biological papers. Figure 3 shows visually the distribution of biological domains in PNAS from 2003 to 2015.

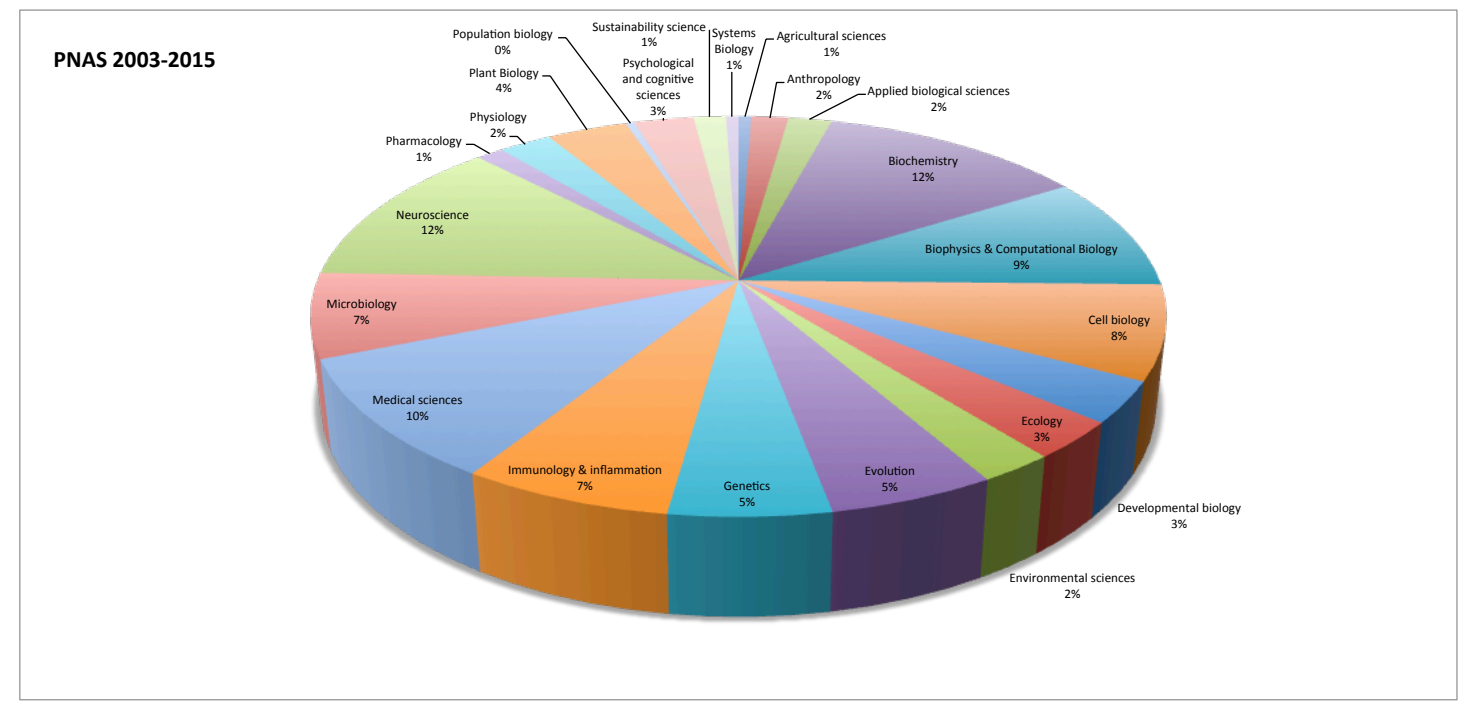

Fig. 3. Biological domains represented in $P N A S$ from 2003 to 2015. This figure shows the relative weight of each biological domain with regard to all the biological papers (not all the scientific papers more generally) published in $P N A S$.

Both the overall representation of each biological domain in PNAS from 2003 to 2015 and the evolution of each domain through time can be of interest. Overall, the six dominant biological domains in PNAS (those that represent strictly more than $5 \%$ of the total biological papers) are, by order of percentage amounts: biochemistry $(12 \%)$, neuroscience $(12 \%)$, medical sciences $(10 \%)$, and computational biology (9\%), immunology and inflammation (7\%), and microbiology (7\%). Even if these disciplines dominate in the long run, their relative representation has sometimes changed through the years. Indeed, as shown in Figure S2 (Supplementary material), some biological domains became more represented while others became less so in $P N A S$ from 2003 to 2015 . For example, biochemistry represented $17 \%$ of the

\footnotetext{
${ }^{8}$ The classification of PNAS papers into precise sections was not frequent in the $1980 \mathrm{~s}$ and the $1990 \mathrm{~s}$ (many papers were attributed to the very broad category "research article"), and became systematic only with the issue of November 12, 1996 (vol. 93 no. 23). As a consequence, all the figures given here (in the Supplementary material) concerning the pre-1996 period must be taken with caution.
} 
biological papers published in $P N A S$ in 2003, but only $9 \%$ in 2015 , while environmental sciences moved from 1\% in 2005 to $4 \%$ in 2015.

The most important question for our present purposes is how the distributions of biological domains in Biology \& Philosophy (Figure 2) and PNAS (Figure 3) compare. The most immediate lessons that can be drawn from this comparison are:

- The representations of biological domains in PNAS and Biology \& Philosophy from 2003 to 2015 are extremely different.

- With regard to evolution, the comparison reveals what could be called the " 5 $60 \%$ rule": evolution represents only $5 \%$ of the papers published in $P N A S$, but approximately $60 \%$ of the papers published in Biology \& Philosophy.

- Several of the most widely represented biological domains in PNAS are absent or almost absent from Biology \& Philosophy. This includes biochemistry $(12 \%$ vs. $2 \%)$, biophysics and computational biology (9\% vs. $0 \%)$, cell biology ( $8 \%$ vs. $0 \%)$, immunology (7\% vs. $0 \%)$, and the neurosciences $(12 \%$ vs. $3 \%)^{9}$.

- The representation of biological domains in Biology \& Philosophy through time remains unaffected by the changes in the representation of biological domains in $P N A S$ : for example, environmental sciences were not more represented in Biology \& Philosophy in 2015 than in 2003, even though this domain increased significantly its representation in PNAS between these two dates.

Thus, the comparison between Biology \& Philosophy and PNAS suggests the existence of a very significant mismatch between the biological domains studied by philosophers of biology and those by biologists themselves. The present analysis gives strength to the remark made by Sarkar and Plutynski (2008) that, given the diversity and richness of the different fields of current biology, a philosophy of biology focused exclusively or almost exclusively on evolution is "myopic". ${ }^{10}$ Although the mismatch described here has been anticipated by many actors in the field (e.g., Griffiths 2008), it seemed important to demonstrate and describe it more clearly. The crucial question now is how this mismatch might be explained.

\section{Possible explanations for the mismatch between biology and philosophy of biology}

This section examines explanations that have been or could be advanced to account for the mismatch between biology and philosophy of biology in terms of distribution of biological domains. I show that many of these explanations are unconvincing. In particular, using examples coming from different disciplines of current biology, I reject the idea that biological fields not focusing directly on evolution do not raise important philosophical problems.

\footnotetext{
${ }^{9}$ The example of the medical sciences (10\% vs. $2 \%$ ) is interesting too, but slightly different because philosophers of medicine often publish their papers in their own journals.

10 "Traditionally, evolution has been the focus of most philosophical attention. While it surely remains true that 'nothing in biology makes sense except in light of evolution' (Dobzhansky, 1973), this tradition within the philosophy of biology is myopic insofar as it ignores much - if not most - of the work in contemporary biology." Sarkar and Plutynski (2008, p. xviii)
} 


\section{A simple historical contingency}

Perhaps the most straightforward explanation is one insisting on historical contingency: according to this explanation, it just happened that the founders, both philosophers and biologists, were interested in evolution. This includes, naturally, David Hull, Michael Ruse, and Marjorie Grene ${ }^{11}$, as well as many others after them (e.g., Brandon 1978; Wimsatt 1980; Sober 1984; Lloyd 1988; Sober 2000). Among biologists who contributed to the emergence of the field of philosophy of biology, evolutionists were clearly dominant (Ernst Mayr, Richard Lewontin, Francisco Ayala, Michael Ghiselin, etc.).

Though this historical contingency is probably part of the explanation, it is clearly not sufficient. This kind of explanation presupposes in part what is in question: it says that philosophy of biology has focused on evolution because its founders were interested in evolution, without questioning who these "founders" are, why they are considered as founders, and why exactly they chose to focus on evolutionary issues. Looking carefully at the history of the philosophy of biology, the "founder-based" argument seems questionable. One of the first philosophers writing specifically about biology in the 1960s and 1970s was Ken Schaffner, who wrote mainly about molecular biology (broadly construed) and about the potential reduction of Mendelian genetics to molecular genetics (Schaffner 1967; Schaffner 1969). Schaffner was not alone in his interest for molecular biology. Reducibility to the molecular level became one of the most intensively discussed topics among the philosophers of biology of the 1970s (e.g., Ruse 1971; Hull 1974; Wimsatt 1976; Darden and Maull 1977). Moreover, an interest for molecular biology has clearly been present in philosophy of biology from the 1970-1980s onward (e.g., Darden and Maull 1977; Kitcher 1982; Kitcher 1984; Burian 1985; Rosenberg 1985; Waters 1990; Sarkar 1991), so what requires an explanation is why this branch of philosophy of biology has not flourished as much as the evolutionary branch. To some extent, therefore, it seems that it is those who did philosophy of evolution who, in retrospect, have been considered as the founders of the field, at least as much as the other way around. ${ }^{12}$ Overall, therefore, historical contingency is probably part of the explanation for the domination of evolution in philosophy of biology, but it cannot be the whole story.

\section{Evolution is more theoretical}

The argument that evolution is more theoretical and therefore philosophically more interesting seems to have been important for some philosophers of biology, particularly Hull. In many statements, Hull says that only evolution offers a genuine scientific theory, in contrast with other biological domains such as physiology and anatomy (e.g., (Hull 1974)) This view raises many difficulties.

\section{i) Is it true that non-evolutionary domains are not theoretical?}

\footnotetext{
${ }^{11}$ Grene was extremely interested in evolution (e.g., Grene 1958) and this explains, at least in part, why Hull (2008) described her as the "grandmother" of philosophy of biology, despite their many disagreements (e.g., Hull 1969).

12 The "invention of predecessors" is a classic phenomenon in science and elsewhere: see, e.g., Canguilhem (2005).
} 
Non-evolutionary domains can be theoretical. To take just a few examples, systems biology, immunology, and ecology have very strong theoretical components, but their theories have not aroused the interest of many philosophers of biology. Even domains that have often been perceived as non-theoretical, for example developmental biology, can in fact offer theories (Minelli and Pradeu 2014), but, here again, few philosophers have studied those theories. Therefore, it seems unlikely that the main reason why philosophers of biology have been so much attracted by evolution is the theoretical nature of this domain as such.

\section{ii) Should evolution be seen exclusively as a theoretical field?}

Clearly evolution offers one unifying framework for all biology, and some aspects of evolution are highly theoretical, but this should not hide the fact that evolution has also a key experimental component. Recent major advances in evolution have come from studies in "experimental evolution", such as those of Richard Lenski, Michael Travisano, and several others (Lenski et al. 1991; Lenski and Travisano 1994; Sniegowski et al. 1997). An exclusive focus on the theoretical dimension of evolution might lead philosophers of biology to miss the importance of these experimental approaches to evolution.

\section{iii) Is the theoretical dimension essential to philosophy of science?}

The focus of some philosophers of biology on theories is a testament of the priority given to theories in philosophy of science more generally (a clear example of this are the debates over the "syntactic" or "semantic" nature of evolutionary theory: e.g., (Ruse 1973; Lloyd 1988)). Starting from the 1980s, several discussions in philosophy of science (including Hacking (1983)), have questioned this focus on theories, emphasizing that many practical and experimental aspects of the sciences could be philosophically stimulating. The attention to experimental and practical aspects of science has also manifested in philosophy of biology, for example in the work of Marcel Weber (2005), Ken Waters (2008), and Ingo Brigandt (2013a), among others. Many philosophers of science today consider that there is much more to philosophy of science than just theories.

\section{Evolution is philosophically more interesting}

If asked why evolution dominates their field, many philosophers of biology might say that evolution is philosophically very interesting, and probably more interesting than other biological fields (e.g., Ruse 1988: 80). Perhaps some fields - such as biochemistry, biophysics, or cell biology - are biologically important, but of little philosophical interest.

The philosophical dimension of evolutionary biology is naturally beyond doubt. Evolutionary theory is rich and "substrate-neutral", that is, it can be applied to many different levels of the biological world - a feature that has played an important role in the major debate over "units of selection" (Lewontin 1970) and evolutionary individuality (Hull 1980). Over the last four decades or so, philosophers of biology have succeeded in showing that analysis of evolutionary biology can make key contributions to both general philosophy of science and general philosophy. Evolution 
can shed light on causality and explanation (for example the status of historical explanations) (e.g., Sober 1984), and the definition of scientific theories (e.g., Lloyd 1988), among other issues. In addition, a careful examination of evolution can have major consequences for some of the most fundamental and traditional debates of philosophy and metaphysics, including the possibility of defining human nature (Hull 1986; Lewens 2012), the definition of natural kinds (e.g., Dupré 1993), the emergence of cognition (Sterelny 2003) and morality (Joyce 2006), or the definition of individuality (Hull 1978; Hull 1980; Godfrey-Smith 2013).

Can other biological domains be as philosophically interesting as evolution? Some examples show that biological domains that do not focus on evolutionary questions can raise major philosophical problems, and in some cases already have done so (though not, or not massively, in Biology \& Philosophy). One obvious example is the philosophy of neuroscience ${ }^{13}$. As we have seen, the neurosciences represent $12 \%$ of the biological papers published in PNAS but only 3\% of the papers published in Biology \& Philosophy. The neurosciences are of high philosophical interest, from at least two points of view (Gold and Roskies 2008; Bickle 2009). First, the neurosciences can contribute to a variety of traditional philosophical problems, as suggested by "neurophilosophy" (Patricia Churchland 1986). This includes our understanding of perception (e.g., Keeley 2002), representation (Bechtel 2001; Bechtel 2016), emotion (Hardcastle 1999a; Prinz 2004), or pain (Hardcastle 1999b). Perhaps classic problems of philosophy of science (e.g., the structure of scientific theories) could be impacted as well, as suggested by Paul Churchland (1989). More generally, many philosophers have suggested that the neurosciences can affect major questions of traditional philosophy and ethics, such as the nature of desire (Schroeder 2004), moral cognition (Prinz 2007), but also free-will, self-control, and personal identity (Roskies 2002). Second, some questions raised by the neurosciences themselves can be worth exploring from a philosophical point of view, including the neural coding of information and the meaning of the word "information" in that context (e.g., Garson 2003), the problem of perceptual binding (i.e., how our perceptions become united into wholes even though all individual features that comprise them are distributed about the brain) (Hardcastle 1997), or the issue of the neural correlates of consciousness (Frith et al. 1999; Rees et al. 2002; Block 2005). Though several of these issues have been examined by philosophers in journals specialized in ethics or philosophy of mind, I suspect that they would be treated differently (and in ways that would usefully complement those pre-existing explorations) if they were to become the focus of papers published in Biology and Philosophy.

Many other biological domains are philosophically interesting. Cell biology ( $8 \%$ in $P N A S$ vs. $0 \%$ in Biology \& Philosophy) raises some deep historical-philosophical questions (e.g., Bechtel 2006), and additional philosophical topics that could be developed further. For example, Bechtel (2010) has analysed the difference (and complementarity) between two trends in biological research about the cell, one that sees the cell as an explanandum, an entity to be decomposed into relevant intracellular mechanisms but that does not figure itself in biological explanations, and the other as an explanans, a functional and explanatorily relevant unit conceived as an integrated and organized system. More generally, cell biology raises crucial questions about what counts as a fundamental unit of life (Canguilhem 1992). Microbiology (7\% in

\footnotetext{
${ }^{13}$ One should keep in mind that philosophers of neuroscience often publish their research in cognitive science journals and in general philosophy of science journals. My point here is simply that very few of them publish their research in Biology \& Philosophy.
} 
PNAS vs. $3 \%$ in Biology \& Philosophy) has generated increasing amounts of philosophical literature in recent years (e.g., Franklin 2007; O'Malley and Dupré 2007; Ereshefsky 2010; O’Malley 2014). However, much philosophy of microbiology has focused on exploring "traditional" evolutionary topics (such as the species concept). Further philosophical work could be done on other aspects of microbiology, such as physiological, developmental and even clinical microbiology. Immunology (7\% in PNAS vs. 0\% in Biology \& Philosophy) has much to say about several philosophical topics, including the definition of biological identity and individuality, and could be used to complement dominant evolutionary approaches to that topic (Tauber 1994; Pradeu 2012; Pradeu 2016). Systems biology14, a new and fastgrowing field, has already generated a rich philosophical literature, for example about part-whole relations, what constitutes a biological system (and which biological units qualify as "systems"), multilevel causation and the emergence of new functions at the system level (O'Malley and Dupré 2005), the possibility of formulating laws or at least design principles in biology (Green 2015), the integration of mechanistic explanation and mathematical explanation (Brigandt 2013b), or the role in silico models can play in comparison with traditional experimental data (MacLeod and Nersessian 2013). Stem cell biology is also philosophically fascinating, for issues as diverse as modelling and interdisciplinarity (Fagan 2013), or the causality of tumour formation (Laplane 2016).

\section{Conclusion: Biologies and philosophy}

This paper describes the significant mismatch in the biological domains studied by philosophers of biology and biologists, respectively, and asks how it can be explained. Obviously, future work will have to address these issues in greater detail. As suggested by two anonymous referees, a careful analysis of the talks given at ISHPSSB meetings and of the philosophy of biology papers published in generalist philosophy of science journals (such as Philosophy of Science, the British Journal for Philosophy of Science, etc.) would be very useful to offer a more balanced and precise picture. I hope I or others will be able to conduct this work in the near future.

Meanwhile, I will try to suggest a more personal conclusion. I have claimed that there is no compelling justification for the domination of evolutionary studies in philosophy of biology. In my closing remarks, I would like to argue that philosophy of biology should now adopt a much more open-minded and encompassing view, by exploring all the domains of today's biology. As the examples examined above show, many areas of the life sciences neglected by philosophers can be of considerable philosophical interest. But what exactly would be the benefits of this more diversified and integrative approach in philosophy of biology? I mention here four benefits.

\section{Bring new biologists on board}

\footnotetext{
${ }^{14}$ Systems biology represents $1 \%$ of the biological papers published in $P N A S$ and $0 \%$ of the papers published in Biology \& Philosophy. The raw numbers indicate that, from 2009 (the year when the category "Systems biology" was created in PNAS) to 2015, PNAS published 240 papers about systems biology, with a tendency to increase over time, while Biology \& Philosophy published 2.
} 
Many philosophers of biology have interacted with evolutionary biologists, and sometimes have even had an influence on their debates. It is likely that many biologists working in other fields would be willing to interact with philosophers, but they would like the latter to share their enthusiasm for their current research topics, which are often quite distant from the issues that are exciting to philosophers. As an example, if one takes the three most recent biological "breakthroughs of the year" decided annually by the leading journal Science (HIV treatment as prevention in 2011; cancer immunotherapy in 2013; the CRISPR system, identified as a prokaryotic immune system and then recognized as genome editing system, in 2015) ${ }^{15}$, none of them has been extensively discussed by philosophers of biology, even though they could all be very stimulating from a philosophical point of view. In fact, recent philosophical work done about the domains examined above (neuroscience, microbiology, immunology, systems biology) have already led to many papers cowritten by biologists and philosophers, which proves that bringing new biologists to philosophy of biology is perfectly possible.

\section{Enrich traditional philosophical questions and/or responses to these questions}

In the same way as philosophers of biology demonstrated that raising issues of general philosophy of science (e.g., causality, explanation, the nature of models and theories) exclusively through the lens of philosophy of physics was problematic, it is equally unsuitable to raise issues of philosophy of biology only through the lens of philosophy of evolution. For example, the question of whether or not biology offers laws has been examined mainly from the point of view of evolution (e.g., Beatty 1995), and perhaps raising this same question from the points of view of biophysics or systems biology would lead to novel answers, or perhaps to the reframing of the question itself. At the very least, it seems that integrating and articulating the answers given by these different domains would be useful.

\section{$\underline{\text { Raise new philosophical issues }}$}

Philosophy of evolutionary biology has given rise to interesting philosophical questions, but those should not be seen as the only philosophically interesting questions. Neuroscience, for example, addresses issues about cognition and the "mind-body" problem (or its dissolution) that echo traditional and crucial questions of philosophy (Churchland 1986; Churchland 2008) but are not raised directly by philosophy of evolutionary biology. Similarly, longstanding philosophical issues about part-whole relations, boundaries, identity, etc., could be informed, or even sometimes significantly transformed, by a better knowledge of cell biology, ecology, immunology, or systems biology.

\section{Enrich evolution itself}

Even for philosophers of biology who would want to maintain that evolution should remain central to philosophy of biology, integrating lessons from a variety of fields

\footnotetext{
${ }^{15}$ In 2012 and 2014, the "breakthroughs of the year" decided by Science concerned physics, not biology.
} 
would still be useful, as it would enrich our view of evolution. Some of the most exciting challenges in current evolutionary biology lie at the interface between evolution and development (e.g., Minelli and Fusco 2008; Wagner 2014), mechanisms of extended inheritance (e.g., Danchin et al. 2011), systems biology and computational biology (e.g., Wagner 2005; Wagner 2008; Koonin 2011), among many other fields (see Laland et al. 2011), and it is clear than many major philosophical issues come forth at these interfaces.

Overall, then, the extension of biological topics advocated here holds promises for philosophy at all levels, from general philosophy to philosophy of science and to philosophy of biology. I can only hope that the new generation of philosophers of biology will take up these topics, and that, thirty years from now, this paper will be considered pointless.

\section{References}

Beatty J (1995) The evolutionary contingency thesis. In: Wolters G, Lennox JG (eds) Concepts, Theories and Rationality in the Biological Sciences. University of Pittsburgh Press, Pittsburgh, pp 45-81

Bechtel W (2016) Investigating neural representations: the tale of place cells. Synthese 193:1287-1321. doi: 10.1007/s11229-014-0480-8

Bechtel W (2006) Discovering cell mechanisms: the creation of modern cell biology. Cambridge University Press, New York

Bechtel W (2010) The cell: locus or object of inquiry? Stud Hist Philos Biol Biomed Sci 41:172-182. doi: 10.1016/j.shpsc.2010.07.006

Bechtel WP (2001) Representations: From Neural Systems to Cognitive Systems. In: Mandik P, Mundale J, Stufflebeam RS (eds) Philosophy and the Neurosciences: A Reader. Blackwell, pp 332-349

Bickle J (2009) Introduction. In: The Oxford Handbook of Philosophy and Neuroscience. Oxford University Press, Oxford; New York, pp 3-10

Block N (2005) Two neural correlates of consciousness. Trends Cogn Sci 9:46-52. doi: 10.1016/j.tics.2004.12.006

Brandon RN (1978) Adaptation and Evolutionary Theory. Stud Hist Philos Sci Part A 9:181-206.

Brigandt I (2013a) Integration in biology: Philosophical perspectives on the dynamics of interdisciplinarity. Stud Hist Philos Sci Part C Stud Hist Philos Biol Biomed Sci 44:461-465. doi: 10.1016/j.shpsc.2013.09.009

Brigandt I (2013b) Systems biology and the integration of mechanistic explanation and mathematical explanation. Stud Hist Philos Biol Biomed Sci 44:477-492. doi: 
Burian RM (1985) On Conceptual Change in Biology: The Case of the Gene. In: Depew D, Weber BH (eds) Evolution at a Crossroads: The New Biology and the New Philosophy of Science. MIT Press, Cambridge, MA, pp 21-42

Byron JM (2007) Whence Philosophy of Biology? Br J Philos Sci 58:409-422.

Canguilhem G (2005) The Object of the History of Sciences. In: Gutting G (ed) Continental Philosophy of Science. Blackwell, Oxford, pp 198-207

Canguilhem G (1992) La théorie cellulaire (1934). In: La connaissance de la vie. Vrin, Paris, pp 43-80

Churchland PM (1989) A neurocomputational perspective: the nature of mind and the structure of science. MIT Press, Cambridge, MA

Churchland PS (1986) Neurophilosophy: toward a unified science of the mind-brain. MIT Press, Cambridge, Mass

Churchland PS (2008) The impact of neuroscience on philosophy. Neuron 60:409411. doi: 10.1016/j.neuron.2008.10.023

Danchin É, Charmantier A, Champagne FA, et al (2011) Beyond DNA: integrating inclusive inheritance into an extended theory of evolution. Nat Rev Genet 12:475486. doi: $10.1038 / \mathrm{nrg} 3028$

Darden L, Maull N (1977) Interfield Theories. Philos Sci 44:43-64.

Dupré J (1993) The disorder of things : metaphysical foundations of the disunity of science. Harvard University Press, Cambridge, Mass

Ereshefsky M (2010) Microbiology and the species problem. Biol Philos 25:553-568. doi: 10.1007/s10539-010-9211-9

Fagan MB (2013) Philosophy of stem cell biology: knowledge in flesh and blood. Palgrave Macmillan, Houndmills, Basingstoke, Hampshire

Franklin LR (2007) Bacteria, Sex, and Systematics. Philos Sci 74:69-95.

Frith null, Perry null, Lumer null (1999) The neural correlates of conscious experience: an experimental framework. Trends Cogn Sci 3:105-114.

Garson J (2003) The Introduction of Information into Neurobiology. Philos Sci 70:926-936. doi: 10.1086/377378

Gayon J (2009) Philosophy of Biology: An Historico-critical Characterization. In: Brenner A, Gayon J (eds) French studies in the philosophy of science : contemporary research in France. Springer, Dordrecht, pp 201-212

Godfrey-Smith P (2013) Darwinian Individuals. In: Bouchard F, Huneman P (eds) From Groups to Individuals: evolution and emerging individuality. MIT Press, Cambridge, MA, pp 17-36

Gold I, Roskies AL (2008) Philosophy of Neuroscience. In: Ruse M (ed) The Oxford 
Handbook of Philosophy of Biology. Oxford University Press, Oxford \& New York, pp 349-380

Green S (2015) Revisiting generality in biology: systems biology and the quest for design principles. Biol Philos 30:629-652. doi: 10.1007/s10539-015-9496-9

Grene M (1958) Two evolutionary theories. Br J Philos Sci 9:110-127.

Griffiths P (2008) Philosophy of Biology. In: Zalta EN (ed) The Stanford Encyclopedia of Philosophy.

Hacking I (1983) Representing and intervening : introductory topics in the philosophy of natural science. Cambridge University Press, Cambridge Cambridgeshire; New York

Hardcastle VG (1997) Consciousness and the neurobiology of perceptual binding. Semin Neurol 17:163-170. doi: 10.1055/s-2008-1040926

Hardcastle VG (1999a) It's Ok to Be Complicated: The Case of Emotion. J Conscious Stud 6:237-249.

Hardcastle VG (1999b) The myth of pain. MIT Press, Cambridge, Mass

Hull D (1969) What philosophy of biology is not. Synthese 20:157-184. doi: 10.1007/BF00413784

Hull D (1980) Individuality and Selection. Annu Rev Ecol Syst 11:311-332. doi: 10.1146/annurev.es.11.110180.001523

Hull DL (2008) The History of the Philosophy of Biology. In: Ruse M (ed) The Oxford handbook of philosophy of biology. Oxford University Press, New York, pp $11-33$

Hull DL (1974) Philosophy of biological science. Englewood Cliffs, NJ, Prentice-Hall Hull DL (1986) On Human Nature. PSA Proc Bienn Meet Philos Sci Assoc 1986:313.

Hull DL (1978) A Matter of Individuality. Philos Sci 45:335-360.

Joyce R (2006) The evolution of morality. MIT Press, Cambridge, Mass

Keeley BL (2002) Making Sense of the Senses: Individuating Modalities in Humans and Other Animals. J Philos 99:5-28. doi: 10.5840/jphil20029915

Kitcher P (1982) Genes. Br J Philos Sci 33:337-359.

Kitcher P (1984) 1953 and all That. A Tale of Two Sciences. Philos Rev 93:335-373. doi: $10.2307 / 2184541$

Koonin EV (2011) The logic of chance: the nature and origin of biological evolution, 1st ed. FT Press, Upper Saddle River, NJ

Laland KN, Sterelny K, Odling-Smee J, et al (2011) Cause and effect in biology revisited: is Mayr's proximate-ultimate dichotomy still useful? Science 334:1512- 
1516. doi: $10.1126 /$ science. 1210879

Laplane L (2016) Cancer stem cells: philosophy and therapies. Harvard University Press, Cambridge, Massachusetts

Lenski RE, Rose MR, Simpson SC, Tadler SC (1991) Long-Term Experimental Evolution in Escherichia coli. I. Adaptation and Divergence During 2,000 Generations. Am Nat 138:1315-1341.

Lenski RE, Travisano M (1994) Dynamics of adaptation and diversification: a 10,000-generation experiment with bacterial populations. Proc Natl Acad Sci 91:6808-6814.

Lewens T (2012) Human Nature: The Very Idea. Philos Technol 25:459-474. doi: $10.1007 / \mathrm{s} 13347-012-0063-\mathrm{x}$

Lewontin RC (1970) The Units of Selection. Annu Rev Ecol Syst 1:1-18. doi: 10.1146/annurev.es.01.110170.000245

Lloyd EA (1988) The structure and confirmation of evolutionary theory. Greenwood Press, New York

MacLeod M, Nersessian NJ (2013) Coupling simulation and experiment: The bimodal strategy in integrative systems biology. Stud Hist Philos Biol Biomed Sci 44:572584. doi: 10.1016/j.shpsc.2013.07.001

Minelli A, Fusco (2008) Evolving pathways: key themes in evolutionary developmental biology. Cambridge University Press, Cambridge, UK; New York

Minelli A, Pradeu T (2014) Towards a Theory of Development. Oxford University Press

O’Malley MA (2014) Philosophy of Microbiology. Cambridge University Press

O’Malley MA, Dupré J (2007) Towards a philosophy of microbiology. Stud Hist Philos Biol Biomed Sci 38:775-779. doi: 10.1016/j.shpsc.2007.09.002

O’Malley MA, Dupré J (2005) Fundamental issues in systems biology. BioEssays News Rev Mol Cell Dev Biol 27:1270-1276. doi: 10.1002/bies.20323

Pradeu T (2012) The Limits of the Self: Immunology and Biological Identity. Oxford University Press, New York

Pradeu T (2016) Organisms or biological individuals? Combining physiological and evolutionary individuality. Biol Philos 31:797-817. doi: 10.1007/s10539-016-9551-1

Prinz JJ (2004) Gut reactions: a perceptual theory of emotion. Oxford University Press, New York

Prinz JJ (2007) The emotional construction of morals. Oxford University Press, Oxford; New York

Rees G, Kreiman G, Koch C (2002) Neural correlates of consciousness in humans. Nat Rev Neurosci 3:261-270. doi: 10.1038/nrn783 
Rosenberg A (1985) The structure of biological science. Cambridge University Press, Cambridge Cambridgeshire; New York

Roskies A (2002) Neuroethics for the New Millenium. Neuron 35:21-23. doi: 10.1016/S0896-6273(02)00763-8

Ruse M (1973) The philosophy of biology. London, Hutchinson

Ruse ME (1971) Reduction, Replacement, and Molecular Biology. Dialectica 25:3972. doi: 10.1111/j.1746-8361.1971.tb00591.x

Sarkar S (1991) Reductionism and functional explanation in molecular biology. Uroboros 1:67-94.

Sarkar S, Plutynski A (2008) A companion to the philosophy of biology. Blackwell Pub, Malden, MA

Schaffner K (1967) Approaches to Reduction. Philos Sci 34:137-147. doi: $10.1086 / 288137$

Schaffner K (1969) The Watson-Crick Model And Reductionism. Br J Philos Sci 20:325.

Schroeder T (2004) Three faces of desire. Oxford University Press, Oxford ; New York

Sniegowski PD, Gerrish PJ, Lenski RE (1997) Evolution of high mutation rates in experimental populations of E. coli. Nature 387:703-705. doi: 10.1038/42701

Sober E (1984) The nature of selection: evolutionary theory in philosophical focus. MIT Press, Cambridge, Mass

Sober E (2000) Philosophy of Biology, 2nd edition. Westview Press

Sterelny K (2003) Thought in a hostile world: the evolution of human cognition. Blackwell, Malden, MA

Tauber AI (1994) The Immune Self: Theory or Metaphor? Cambridge University Press, Cambridge

Wagner A (2008) Neutralism and selectionism: a network-based reconciliation. Nat Rev Genet 9:965-974. doi: 10.1038/nrg2473

Wagner AJ 26- (2005) Robustness and evolvability in living systems. Princeton University Press, Princeton, NJ

Wagner GP (2014) Homology, genes, and evolutionary innovation. Princeton University Press, 2014, Princeton

Waters CK (1990) Why the Anti-Reductionist Consensus Won't Survive: The Case of Classical Mendelian Genetics. PSA Proc Bienn Meet Philos Sci Assoc 1990:125-139.

Waters CK (2008) How Practical Know-How Contextualizes Theoretical Knowledge: Exporting Causal Knowledge from Laboratory to Nature. Philos Sci 75:707-719. doi: $10.1086 / 594516$ 
Weber M (2005) Philosophy of experimental biology. Cambridge University Press, Cambridge, UK; New York

Wimsatt WC (1980) Randomness and perceived-randomness in evolutionary biology. Synthese 43:287-329. doi: 10.1007/BF00413929

Wimsatt WC (1976) Reductive Explanation: A Functional Account. In: Cohen RS, Hooker CA, Michalos AC, Evra JWV (eds) PSA 1974. Springer Netherlands, pp 671710 